\title{
Development of a Catchment Management Tool to Assess Environmental Risk from Nutrient Loadings Using Open Source GIS
}

\author{
Ian Packham, Eva Mockler, and Michael Bruen \\ UCD Dooge Centre for Water Resource Research, School of Civil, \\ Structural and Environmental Engineering, \\ University College Dublin, Belfield, Dublin 4, Ireland \\ \{i.packham, eva.mockler, michael.bruen\} @ucd.ie
}

\begin{abstract}
A Catchment Management Tool (CMT) is being developed for the Irish Environmental Protection Agency (EPA) that will allow River Basin Managers to evaluate the environmental risk from organic and inorganic nutrient loadings due to various land uses and human activities. The CMT was built using Open Source GIS (Geographical Information System) software, to facilitate development and widen the research user-base of the tool. The user interface of the CMT is designed to be flexible to allow local knowledge to be included in the system as well as the possibility to try what-if scenarios in relation to environmental assessment. Contaminant loadings are calculated from publicly available data and hydrogeologically susceptible areas (HSAs) are formed by combining soil and geological GIS layers. Further combinations of Loadings and HSAs allow Critical Source Areas to be delineated that identify areas contributing significant amounts of a given contaminant to any selected water body.
\end{abstract}

Keywords: Catchment Management, Critical Source Areas, Open Source GIS Software, Contaminant Loadings, Hydrogeology, Susceptibility.

\section{Introduction}

In response to the European Union's Water Framework Directive (WFD) requirements that River Basin Districts meet good quality status by 2015, the Irish Environmental Protection Agency (EPA) has commissioned a Catchment Management Tool (CMT) to assist in planning its activities. The CMT is one of the outputs of the Pathways Project, a multidisciplinary collaborative project that aims to improve understanding of hydrological and hydrogeological pathways of water-borne nutrient transport. The knowledge gained from this and other recent projects will inform the CMT and in particular the evaluation of environmental risk due to nutrient loadings.

This paper begins by describing the development of the Catchment Management Tool using Open Source Geographical Information System (GIS) software. Open Source software was chosen during the design and development stage of the CMT for fast, accessible ongoing software development and to widen the potential research user-base of the tool. Then the paper describes the data sources and methods used to 
compute the nutrient loadings for a chosen catchment and thus how the various information sources are combined to produce Critical Source Areas of environmental risk. The paper concludes with potential further applications of the CMT, such as varying loadings due to land-use change and other what-if scenarios. The flexible nature of the CMT is designed to help river basin managers select appropriate measures to achieve good WFD status.

\subsection{Critical Source Areas}

Critical Source Areas are defined as those areas that contribute a disproportionally high pollutant loading to the receiving river, and occur where high loadings coincide with hydrogeologically susceptibility areas (HSAs). HSAs are those areas that are sensitive to a given contaminant (such as the nutrients nitrogen or phosphorous) in relation to a given receptor (such as groundwater or stream/lake). The coincidence of a sensitive area with the likelihood of high loading of that contaminant indicates a possible environmental risk. When defined in this way, critical source areas can be delineated using GIS layers and appropriate factors.

\section{Software Design}

\subsection{Free and Open Source Software for Geospatial}

Open Source software often allows for a flexible development environment because the software in question is often designed to be easy to set up and interact with other software [1]; in contrast to proprietary software that is often designed as a stand-alone system. The Open Source Geospatial Foundation (OSGeo [2]) is the umbrella organization that supports collaborative projects and organizes the annual international Free and Open Source Software for Geospatial (FOSS4G) conference. As well as the projects overseen by OSGeo, there are a large number of other GIS projects listed at [3] and [4] and reviewed, for example, in [5].

The GIS desktop viewer chosen for the Pathways CMT was Quantum GIS (QGIS) [6] which can view multiple sources of GIS data, such as ESRI shapefiles, Raster files and databases. The principal data source is the PostgreSQL [7] database which can be spatially enabled using PostGIS [8]. The advantage of using such a database is that the available data can be processed and stored for viewing, in this case via the QGIS Python plugin architecture. Working copies of data can be saved as individual projects and updated to simulate separately different scenarios. Other Open Source software combinations are available, but the QGIS / PostGIS pairing was seen as the most flexible option for the Pathways project.

\subsection{Three Levels of Interaction}

To allow for different levels of prior knowledge and GIS experience for the users, a range of levels of interaction is provided in the user interface, see Fig. 1.

Level 1: Source Layers. At the first level of interaction, the user can choose the basic source data to view as GIS-layers for the catchment of interest, such as soil properties, 
geology and land-use as well as potential point sources of contaminants. This data is pre-processed so the user can easily view data of interest with minimal interaction; summary reports and statistics are readily available.

Level 2: Static Analysis Layers. At the next level of interaction, users can choose a specific catchment and view in detail the loadings and static critical source areas formed by combining the Level 1 layers. Initially the data is created automatically from default data and parameters, but the user can choose to update this data, if they have more local knowledge or experience of the actual processes involved.

Level 3: Dynamic Analysis Layers. The final level of interaction requires the user to input hydrological data specific to the catchment. The more complicated lateral flows are modeled using a rainfall-runoff model, producing dynamic critical source areas.

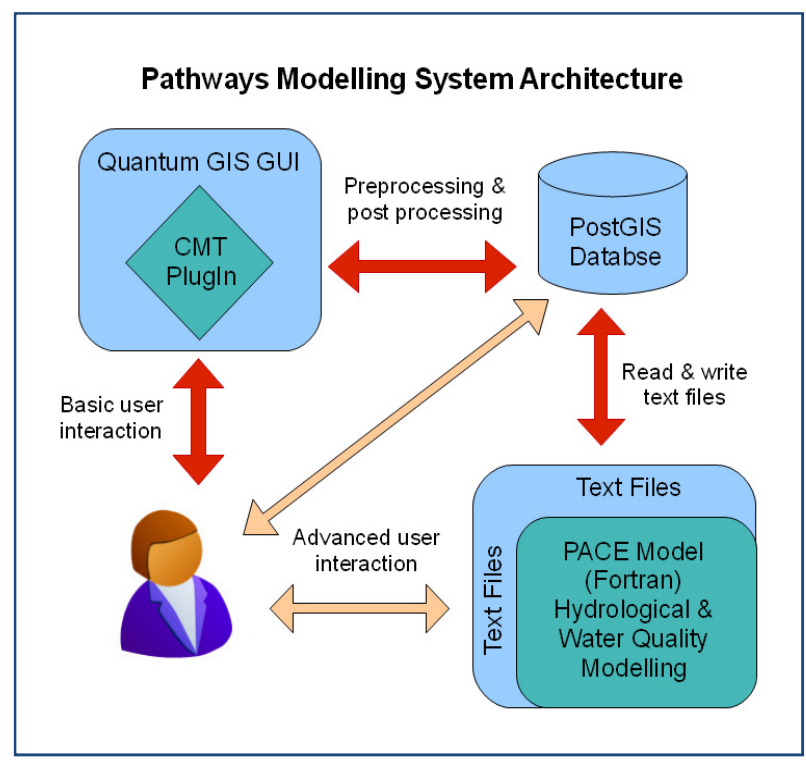

Fig. 1. CMT user interaction diagram

\subsection{Flexible Software Design}

The software was designed as a loosely coupled system so that individual modules can be developed independently and replaced if necessary in the future. The QGIS software is used to view the GIS data; Fig. 2 shows an example, on the left hand side is the layer legend. A plugin written in the Python language lets the user choose which data to load from the PostGIS database (right hand side of Fig. 2). The Python code uses the QGIS application programming interface (API) to define different types of data needed for the CMT plugin and loads this via the database API into QGIS. Summary data and statistics of the relevant layers are easily computed in the plugin. The data has been preprocessed to speed up access for Level 1 Source Layers but also 
to allow combinations of data sources to be intersected "on the fly" (created dynamically) for Level 2 Static Analysis Layers. New data tables are created in the database using SQL (structured query language) and PostGIS spatial functions.

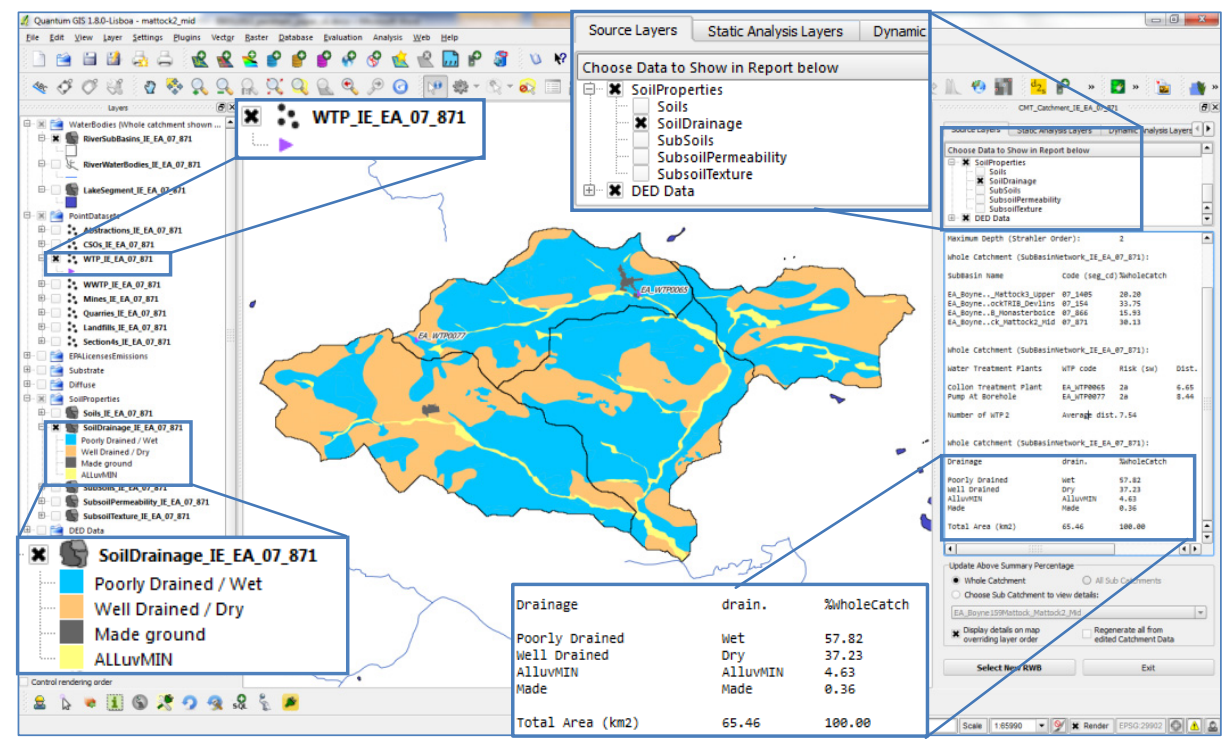

Fig. 2. Screenshot of the CMT - note usual GIS tools are provided by QGIS, the plugin to the right allows the user to choose data layers and view summary statistics of those layers below

Some tables in Level 2 are copies of Level 1 source layers and can be edited by the user. Functionality to change the underlying data is available in QGIS and many other desktop GIS systems. The user might modify the data because, for example, they might know that the in-built default loading values are not appropriate and should be changed or want to simulate changes in, for instance, land-use. After updating the data source, all the other related data tables can be updated from one button click and the outcome of those changes will be immediately seen.

For Level 3, the Pathways Computational Engine (PACE) has been written as a standalone FORTRAN package [9]. Communication with the CMT and database is undertaken only in the form of reading and writing text files. This loose coupling means that the Computational Engine can be developed in parallel with the GIS component and can be amended without affecting the rest of the CMT.

\section{Evaluating Environmental Risk}

\subsection{Source Layers}

Geological and soil mapping information were supplied by the EPA and GSI (Geographical Survey of Ireland) in digital form. Derivatives of the EPA / Teagasc (Irish Agriculture and Food Development Authority) soil maps [10] include soil drainage and subsoil permeability. Other relevant maps include aquifer type, groundwater 
vulnerability [11], Corine land-cover, slope and lakes, a number of these were combined to make the national recharge map [12]. Point sources such as landfills, water treatment plants and registered IPPC (integrated pollution prevention and control) facilities are also included as well as possible hazards such as abstractions and quarries. These maps are all available to view in Level 1 of the CMT (Fig. 2).

\subsection{Calculating Nutrient Loadings}

In the CMT, contaminant loadings to land surfaces are calculated from publicly available data from the Irish Central Statistics Office (CSO). Population figures and the number of houses and type of sewage system that serves each house [13] are available. Land use and the number and type of animals in an Electoral District is provided by the Census of Agriculture [14] which will soon be updated from 2000 to 2010 data. This data is then used to calculate nutrient (Nitrogen and Phosphorous) loading to different hydrological pathways using the Groundwater Task Team (GTT) [15] methodology, modified for Irish settings by the EPA.

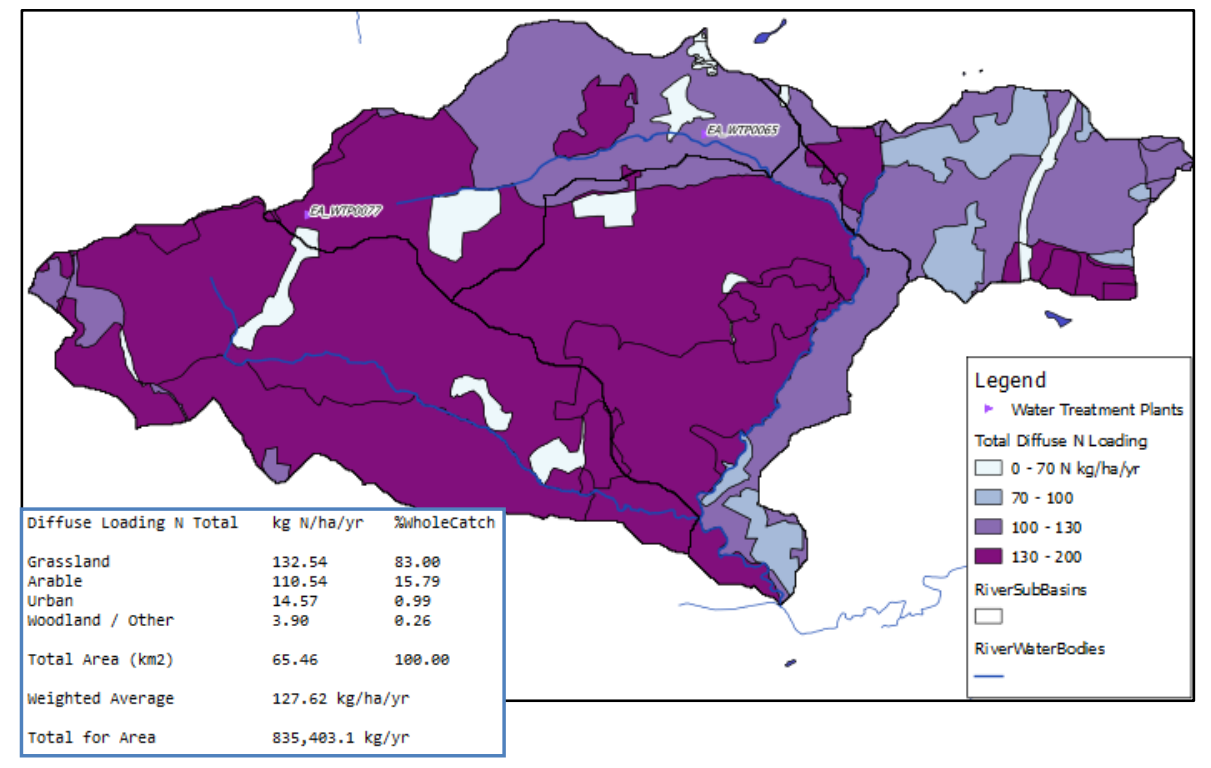

Fig. 3. Example of total input Nitrate loading to the Mattock_mid catchment, on the border of Co Louth and Co Meath in Ireland; inset shows averages broken down by land-use

The hydrological pathways are modeled at river basin sub-catchment level (average area $13 \mathrm{~km}^{2}$ ), so intersection of these with the Irish Electoral District (average area $20 \mathrm{~km}^{2}$ ) gives a coarse variation in loadings across the chosen catchment. An example output of the loadings calculated for nitrate by the CMT is shown in Fig. 3, including a statistical summary. 
The GTT methodology also models, in an empirical way, the processes of the nutrient going through the soil and to the particular receptor that is required to model attenuation processes. For example leaching in Grassland Pastures is calculated using NCycle_IRL [16]. Leaching of Nitrogen is related to soil drainage or texture, so the combination of the loadings map (Fig. 3) and the soil drainage map (Fig. 2) are used to create a loading map of $\mathrm{N}$ from soil drainage (not shown).

\subsection{Creating Hydrogeologically Susceptible Areas (HSAs)}

Hydrogeologically susceptible areas are those areas that are sensitive to a given nutrient reaching a given water body receptor. Creating these layers requires identifying the soil or geological properties that are relevant through literature review, expert opinion or empirical analysis. For example, for nitrogen to groundwater, the combination of subsoil permeability and depth to bedrock is used to determine ranges of susceptibility. The EPA has published a risk-based methodology for single house treatment system that includes a number of susceptibility factors [17]; they also consider denitrification in bedrock for the Groundwater pathway. These factors are being reviewed and modified for use in the CMT.

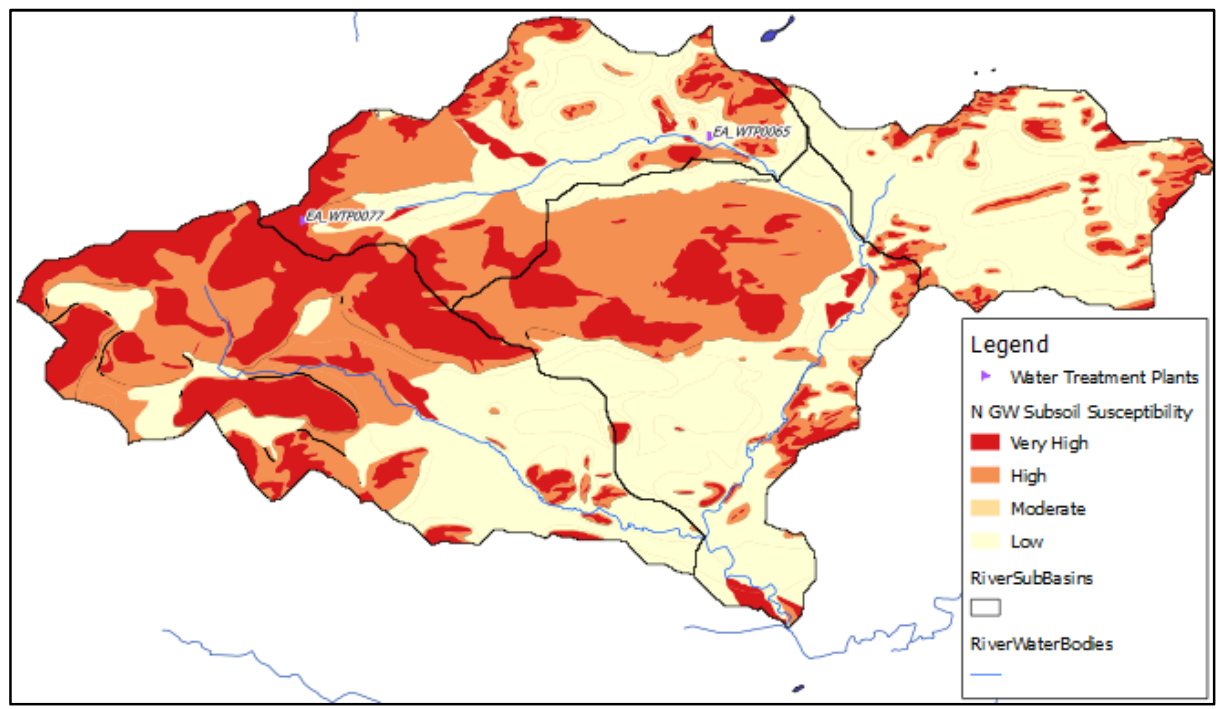

Fig. 4. Hydrogeologically Susceptible Areas (HSAs) of Nitrogen to the Groundwater receptor for the Mattock_mid catchment

Fig. 4 shows an example of the HSAs derived for the Mattock catchment, in the North East of Ireland, for Nitrogen to groundwater. Very High and High susceptibility relate to areas of extreme vulnerability (subsoil less than $3 \mathrm{~m}$ subsoil thick) or highly permeable subsoils. These categories can be given quantitative risk values which in effect are the attenuation rates of nitrogen to groundwater. 
Susceptibility maps for phosphorous to groundwater can be created using the same procedure. Susceptibility to surface water receptors is more problematic as no temporal variation is considered when using the GIS layers. Multiple receptors might also exist in the catchment (in terms of lakes and streams), so only the loading, mobilization and delivery to the local surface water receptor is being considered. The computational engine in Level 3 of the CMT has the capabilities to model the lateral flow and temporal dynamics required for generic surface water receptors.

\subsection{Critical Source Areas (CSAs)}

By combining the Loadings information with the Hydrogeological Susceptibility information it is possible to create Critical Source Area (CSA) maps for each contaminant. When intersecting the maps, the loadings rates from soil drainage can be multiplied by the attenuation rates or other factors derived from the susceptibility maps. The amount of loading that reaches groundwater also needs to take into account as well as the proportion of effective rainfall involved.

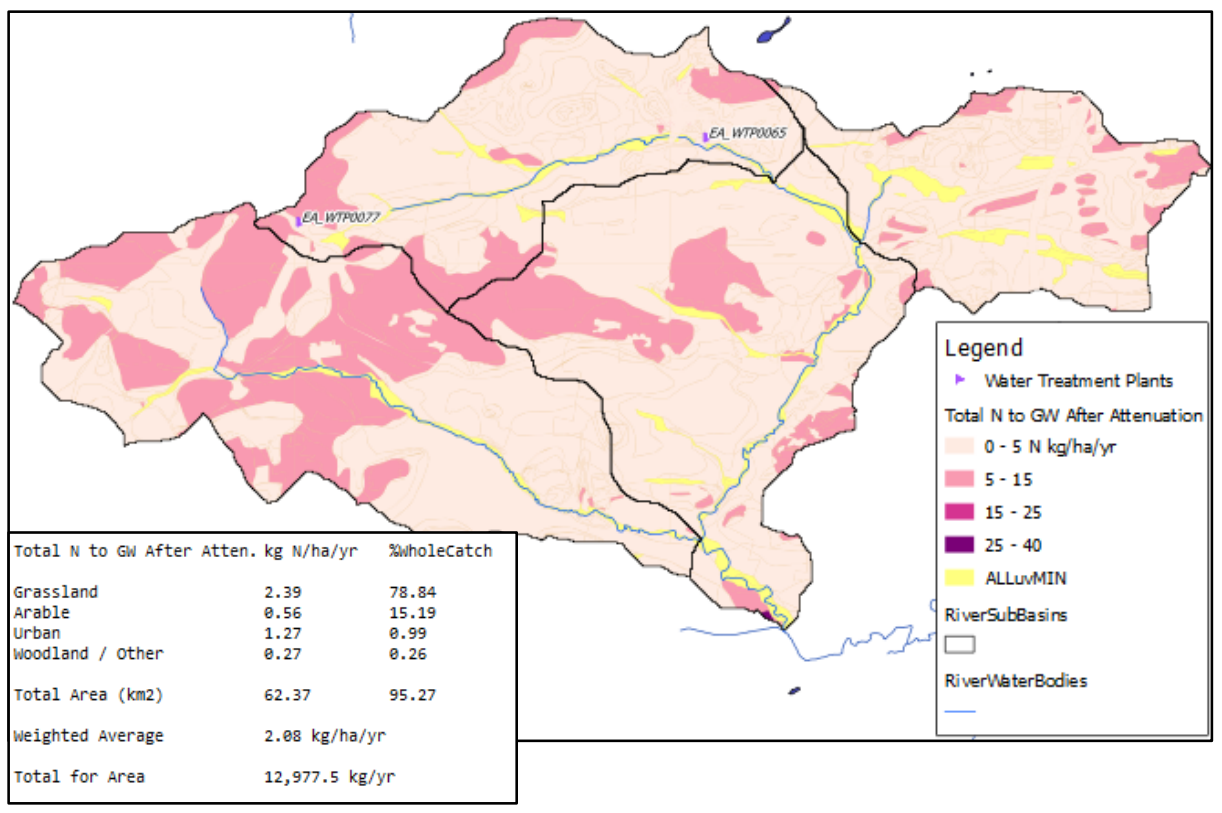

Fig. 5. Critical Source Areas for Nitrogen to Groundwater receptor from diffuse sources; this is final loading after attenuation for Mattock_mid catchment; inset shows averages

The national recharge map [12] is available within the CMT which includes effective rainfall and recharge coefficient. The latter coefficient determines the amount of effective rainfall that will reach the groundwater depending on the hydrogeological category of the area. Most of the Mattock catchment shown in the figures is underlain by a "non-productive" aquifer, that is, it does not have the storage capacity or transmission capability to supply more than a few houses. This is simulated in the Recharge Map by a "cap" that limits the amount of water that the aquifer will accept. 
The recharge cap has an additional effect on the model output as it is assumed that excess rainfall is effectively rejected by the aquifer. In the CMT, a modified recharge coefficient is used that takes into account the recharge cap for non-productive aquifers. Fig. 5 shows the Critical Source Areas to groundwater after combining loadings with soil drainage, the attenuation factors and modified recharge coefficients.

\section{Further Applications and What-If Scenarios}

The CMT is designed to be user friendly by pre-processing as much of the available data as possible so an initial overview can be evaluated by the user or River Basin District Manager very quickly. If the Manager is aware, from local knowledge, of inaccuracies in the underlying loadings data or subsequent output, then changes to the input data and parameters are allowed because copies of the original data can be saved under a different project name. This flexibility also allows for what-if scenarios to be generated as the user can change the loadings data to simulate an increase in, for instance, inorganic fertilizer or leakage at a waste water treatment facility, for example. Also a change in land-use could be simulated by allowing changes to the copy of the Corine land-cover layer. So a change in arable land to urban could be simulated or vice versa. It might also be possible to simulate the effects of climate change by adjusting meteorological inputs or changing the properties of the soil or geology layers and analyze the outcome in the Critical Source Areas.

\section{Conclusions}

A Catchment Management Tool (CMT) is under development for the Irish EPA. The user interface of the CMT is designed to be flexible to allow local knowledge to be included in the system as well as the possibility to try what-if scenarios in relation to environmental assessment. Contaminant loadings are calculated from publicly available data and hydrogeologically susceptible areas (HSAs) are formed by combining soil and geological GIS layers. Further combination of Loadings and HSAs allow Critical Source Areas to be delineated that identify high risk areas from a given contaminant to a receptor of interest.

This paper has described the software architecture of the CMT and the data sources required for the loadings and geological susceptibility layers. Examples of critical source area maps produced from the CMT were shown. Changes in those maps due to user interaction can be used to simulate the changes in environmental risk due to possible future scenarios. Initial feedback suggests the tool will be useful for the EPA and River Basin District Managers; further user testing and validation of the loading and attenuation rates is required before final release.

Acknowledgments. The Pathways Project is an EPA STRIVE funded project (2007W-CD-1-S1), the collaborative partners are Queens University Belfast, University College Dublin and Trinity College Dublin. The authors would also like to thank the project Steering Committee for invaluable discussion and advice. 


\section{References}

1. Sanz-Salinas, J.-G., Montesinos-Lajara, M.: Current Panorama of the FOSS4G Ecosystem. Novatica X(2), 43-51 (2009)

2. Open Source Geospatial Foundation, http: / /www. osgeo.org

3. Open Source GIS, http: / /wWw . opensourcegis . org

4. Free and Open Source GIS, http: / / www. freegis . org

5. Steiniger, S., Bocher, E.: An Overview on Current Free and Open Source Desktop GIS Developments. Int. J. of Geographical Information Science 23(10), 1345-1370 (2008)

6. Quantum GIS, http: //www. qgis.org

7. PostgreSQL, http: //www. postgresql . org

8. PostGIS, http://www.postgis.org

9. Mockler, E., Bruen, M.: A variable-structure catchment model as the engine for a water quality decision support tool facilitating scientific debate and collaboration. In: Seppelt, R., Voinov, A.A., Lange, S., Bankamp, D. (eds.) International Congress on Environmental Modelling and Software - iEMSS 2012 (2012)

10. Fealy, R.M., Green, S., Loftus, M., Meehan, R., Radford, T., Cronin, C., Bulfin, M.: Teagasc EPA Soil and Subsoils Mapping Project-Final Report. Volume I, Teagasc, Dublin (2009)

11. DELG/EPA/GSI: Groundwater Protection Schemes. Department of the Environment and Local Government, Environmental Protection Agency and Geological Survey of Ireland (1999)

12. Hunter Williams, N., Misstear, B., Daly, D., Johnston, P., Lee, M., Cooney, P., Hickey, C.: A National Groundwater Recharge Map for Ireland. National Hydrology Conference (2011)

13. CSO, Small Area Population Statistics (SAPS) (2006), http: / / census. cso.ie/census / ReportFolders/ReportFolders.aspx

14. CSO, Census of Agriculture 2000 Detailed Results: (2000), http: / /www. cso.ie/px/pxcoa2000/database/ censusofagriculture2000/censusofagriculture2000.asp

15. Groundwater Task Team: Cumulative Nitrogen and Phosphorus Loadings to Groundwater, produced by ENTEC on behalf of the Scottish Environment Protection Agency, the Environment Agency (England \& Wales), the Environmental Protection Agency and the Northern Ireland Environment Agency (2010)

16. del Prado, A., Scholefield, D., Brown, L.: NCYCLE_IRL: A model to predict $\mathrm{N}$ fluxes in Irish grasslands. Environmental Protection Agency, Ireland (2005)

17. EPA: A risk-based methodology to assist in the regulation of Domestic Waste Water Treatment Systems. Environmental Protection Agency, Ireland (2013) 